\title{
Neurodevelopment in Children Exposed to Zika Virus: What Are the Consequences for Children Who Do Not Present with Microcephaly at Birth?
}

\author{
Paula Fabiana Sobral da Silva 1,2,*, Sophie Helena Eickmann ${ }^{3}{ }^{-}$, Ricardo Arraes de Alencar Ximenes ${ }^{1}$, \\ Celina Maria Turchi Martelli ${ }^{4}\left({ }^{(0}\right.$, Elizabeth B. Brickley ${ }^{5}{ }^{(0}$, Marília C. Lima ${ }^{3}$, Ulisses R. Montarroyos ${ }^{1}$, \\ Maria Durce Costa Gomes de Carvalho ${ }^{1,2}$, Laura Cunha Rodrigues ${ }^{5}$, Thalia Velho Barreto de Araújo ${ }^{6}$, \\ Liana O. Ventura ${ }^{7}$, Danielle Maria da Silva Oliveira ${ }^{1}$, Regina Coeli Ferreira Ramos ${ }^{8}$, \\ Demócrito de Barros Miranda-Filho ${ }^{1}$ and on behalf of the Microcephaly Epidemic Research Group (MERG) ${ }^{\dagger}$
}

1 Pós-Graduação em Ciências da Saúde, Universidade de Pernambuco, Recife 50100-010, Brazil; raaximenes@uol.com.br (R.A.d.A.X.); ulisses.montarroyos@upe.br (U.R.M.);

mdurce2@gmail.com (M.D.C.G.d.C.); dlsilva@gmail.com (D.M.d.S.O.); demofilho@gmail.com (D.d.B.M.-F.)

2 Departamento de Neurologia Infantil, Hospital Universitário Oswaldo Cruz, Recife 50100-130, Brazil

3 Departamento de Pediatria, Universidade Federal de Pernambuco, Recife 50670-420, Brazil;

sophie.eickmann@gmail.com (S.H.E.); limamc@gmail.com (M.C.L.)

check for

updates

Citation: Sobral da Silva, P.F.; Eickmann, S.H.; Ximenes, R.A.d.A.; Martelli, C.M.T.; Brickley, E.B.; C. Lima, M.; Montarroyos, U.R.; Carvalho, M.D.C.G.d.; Rodrigues, L.C.; Araújo, T.V.B.d.; et al. Neurodevelopment in Children Exposed to Zika Virus: What Are the Consequences for Children Who Do Not Present with Microcephaly at Birth? Viruses 2021, 13, 1427. https://doi.org/10.3390/v13081427

Academic Editors: Emma Mohr and Regina Rowe

Received: 31 May 2021

Accepted: 15 July 2021

Published: 22 July 2021

Publisher's Note: MDPI stays neutral with regard to jurisdictional claims in published maps and institutional affiliations.

Copyright: () 2021 by the authors. Licensee MDPI, Basel, Switzerland. This article is an open access article distributed under the terms and conditions of the Creative Commons Attribution (CC BY) license (https:// creativecommons.org/licenses/by/ $4.0 /)$.
4 Instituto Aggeu Magalhães-Fundação Oswaldo Cruz (Fiocruz), Recife 50740-465, Brazil; turchicm@gmail.com

5 Department of Infectious Disease Epidemiology, London School of Hygiene \& Tropical Medicine, London WC1E 7HT, UK; elizabeth.brickley@1shtm.ac.uk (E.B.B.); laura.rodrigues@lshtm.ac.uk (L.C.R.)

6 Departamento de Medicina Social, Universidade Federal de Pernambuco, Recife 50670-420, Brazil; thalia.araujo@ufpe.br

7 Departamento de Oftalmologia, Fundação Altino Ventura, Recife 52171-011, Brazil; lianaventuramd@gmail.com

8 Departamento de Infectologia Pediátrica, Hospital Universitário Oswaldo Cruz, Recife 50100-130, Brazil; coeliramos@hotmail.com

* Correspondence: paulafsobral@yahoo.com.br

+ Membership of the Microcephaly Epidemic Research Group is provided in the acknowledgments.

Abstract: The relation of Zika virus (ZIKV) with microcephaly is well established. However, knowledge is lacking on later developmental outcomes in children with evidence of maternal ZIKV infection during pregnancy born without microcephaly. The objective of this analysis is to investigate the impact of prenatal exposure to ZIKV on neuropsychomotor development in children without microcephaly. We evaluated 274 children including 235 ZIKV exposed and 39 controls using the Bayley-III Scales of Infant and Toddler Development (BSIDIII) and neurological examination. We observed a difference in cognition with a borderline $\mathrm{p}$-value $(p=0.052): 9.4 \%$ of exposed children and none of the unexposed control group had mild to moderate delays. The prevalence of delays in the language and motor domains did not differ significantly between ZIKV-exposed and unexposed children (language: $12.3 \%$ versus $12.8 \%$; motor: $4.7 \%$ versus $2.6 \%$ ). Notably, neurological examination results were predictive of neurodevelopmental delays in the BSIDIII assessments for exposed children: $46.7 \%$ of children with abnormalities on clinical neurological examination presented with delay in contrast to $17.8 \%$ among exposed children without apparent neurological abnormalities $(p=0.001)$. Overall, our findings suggest that relative to their unexposed peers, ZIKV-exposed children without microcephaly are not at considerably increased risk of neurodevelopmental impairment in the first 42 months of life, although a small group of children demonstrated higher frequencies of cognitive delay. It is important to highlight that in the group of exposed children, an abnormal neuroclinical examination may be a predictor of developmental delay. The article contributes to practical guidance and advances our knowledge about congenital Zika.

Keywords: child development; congenital Zika; Bayley scales; paediatric cohort; neuroclinical examination 


\section{Introduction}

The link of Zika virus (ZIKV) to neurological impairment was described based on the outbreak of congenital anomalies observed in Brazil beginning in October 2015 [1-3]. The short-term risks of congenital ZIKV infections are already known and the impairment of neurodevelopment is evident in children with moderate to severe microcephaly [4-6]. However, the risk of developmental delays in children with evidence of maternal ZIKV infection during pregnancy born without microcephaly remains unknown [7-9].

Recognizing that congenital ZIKV infections may result in later-life consequences for children born 'apparently asymptomatic' for Congenital Zika Syndrome (CZS), the Microcephalic Epidemic Research Group (MERG) followed up a cohort of exposed children in order to identify abnormalities detected at later ages [10]. This paper reports on neurological and neurodevelopmental findings in children with no abnormal findings identified at birth, such as microcephaly, born to mothers who had evidence of ZIKV infection in pregnancy.

In a previously published study, the MERG conducted a neurodevelopmental assessment with a screening instrument and found a gradient of risk of developmental delay according to head circumference. Children with severe microcephaly were at highest risk for delays, while normocephalic ZIKV-exposed children had similar risks as control children [11]. With the current study, we sought to expand the assessment by using the Bayley-III Scales of Infant and Toddler Development (BSIDIII), which is a more specific instrument for evaluating cognitive, language, and motor development [12,13].

Since standardized instruments, such as the BSIDIII, are resource intensive and require lengthy evaluation times, specialized equipment investment, and trained professionals, they often have limited utility outside of a research setting. Therefore, the authors also examined complementary clinical markers that would correlate with the BSIDIII results and facilitate the identification and early referral of children at a higher risk of developmental delays for a more comprehensive assessment.

This investigation is part of a 5 year longitudinal study of the impacts of ZIKV infections during pregnancy and its main objective is to investigate the neuropsychomotor development of a group of children born in the state of Pernambuco, Brazil, with prenatal exposure to ZIKV without microcephaly.

\section{Materials and Methods}

\subsection{Study Design}

This investigation is a cross-sectional study including children followed-up as part of an ongoing prospective cohort (MERG-Paediatric Cohort) born between December 2015 and February 2019, during and after the peak of a microcephaly epidemic that occurred in northeastern Brazil [10].

\subsection{Setting}

The study was conducted at the Hospital Universitário Oswaldo Cruz, which is a reference hospital providing paediatric neurological care in Recife, Pernambuco, Brazil. The study was conducted by a multidisciplinary team, which included professionals trained in neurodevelopmental assessment. Before assessment, caregivers signed informed consent forms for their children's participation. Ethical approval for follow-up in the MERG Paediatric Cohort was provided by a local institutional review board (CAAE: 52803316.8.0000.5192).

\subsection{Participants}

We studied 274 children who completed neurodevelopmental evaluation using the BSIDIII instrument. We compared outcomes between an exposed group of 235 children born without microcephaly to mothers with evidence of ZIKV infection during pregnancy (MERG Pregnant Women Cohort/MERG-PWC) and a control group of 39 children without microcephaly, other brain abnormalities detectable by transfontanellar ultrasonography 
(TF-US) at birth, or other major malformations typical of CZS who were initially recruited as controls in the MERG case-control study [14]. All controls tested negative by qRT-PCR for Zika virus and by capture-IgM ELISA for IgM antibodies and were born to mothers who tested negative for ZIKV at the time of delivery. Exposure to ZIKV during pregnancy was based on a combination of longitudinal data from molecular (qRT-PCR), serologic (IgM e IgG3), and plaque reduction neutralization tests (PRNT) for ZIKV. Maternal ZIKV exposure was categorized according to the degree of evidence of infection. Pregnant women were classified as positive, suspected, or negative. The positive group was divided into three subcategories (robust, moderate, and limited evidence) according to the level of diagnostic evidence. Robust evidence was defined by RT-PCR +, seroconversion, or at least two positive serologic tests (IgM or IgG3) and PRNT50; moderate evidence was defined by IgM or IgG3 + or Seroconversion by PRNT50; and limited evidence as PRNT50 + (in pregnancy or within 6 months post-pregnancy). Suspected cases were defined as PRNT50 titer $\geq 20$ and $<100$ (in pregnancy or 1 month post-pregnancy) or a non-negative result (unspecified titter $\geq 20$ ) in pregnancy or within 1 month post-pregnancy. Negative cases had negative nucleic acid test and negative serologic tests. In the present study we included children born to mothers classified as positive $(82.1 \%)$ or suspected $(17.9 \%)$. A total of 76 mothers out of 235 had a positive PCR. The others were classified according to the other laboratory criteria. All recruited pregnant women with rashes had been notified to the Health Secretariat of the State of Pernambuco $[15,16]$.

\subsection{Clinical Assessment}

Participants were evaluated by different specialists of the MERG team by using standardized protocols. Paediatric neurologists examined children for the following: seizures, impairment of consciousness/behavior, localized motor deficits, altered tonus or muscular trophism, pyramidal signs, developmental milestones (e.g., motor and language), reflex reactions, behavior, and responses to visual and auditory stimuli. TF-US was performed within the first six months of life to assess presence of calcifications, tecidual hypoplasia or atrophy, corpus callosum agenesis or dysgenesis, and ventricular abnormalities. When there was a clinical indication, children had computed tomography (CT) or magnetic resonance (MRI) brain scan performed. Ophthalmological evaluation included specialized tests, such as RetCam (Natus Medical Inc., Pleasanton, CA, USA), eye structural evaluations, and visual acuity testing.

Maternal demographic data and medical histories were collected through caregiver interview. Neonatal and postnatal clinical characteristics were collected during hospitalization and outpatient follow-up by the research team as well as a review of medical records.

\subsection{Neurodevelopment Assessment}

Children were referred for neurodevelopmental assessment (BSIDIII) as they participated in regular evaluations with the specialists from the research group, prioritizing the chronological proximity of these children to annual periodic evaluations and the availability of the tests. We evaluated with Bayley 235/336 (69.9\%) of the MERG-PWC and 39/46 $(84.8 \%)$ of the controls. The evaluations took place at the Hospital Universitário Oswaldo Cruz between June 2017 and March 2020 and included children aged 6 to 42 months. For premature children, adjustments were made to their chronological age to reflect gestations of $<40$ weeks. For those children who underwent two Bayley assessments, we considered the ones at the oldest age in this analysis since we assumed that the results of neuropsychomotor assessment in older children would be more predictive of the long-term developmental patterns [17]. We also analyzed the results of the Bayley assessment in relation to the trimester of pregnancy in which the infection occurred. At the end of the assessment, all caregivers were informed of their child's results and received guidance for home stimulation. 


\subsection{Data Management and Statistical Analysis}

All children who met the inclusion criteria and completed the neurodevelopmental evaluation were included. Data were double entered into a secure 'Shared Data Platform' designed and protected by the Informatics Sector of the Aggeu Magalhães Institute/Fiocruz/Pernambuco. Analyses were performed using the Statistical Package for the Social Sciences (SPSS), version 15.

The analysis was conducted in two steps. In the first step, we compared the exposed children with the control group in relation to Bayley scores. In the second step, we investigated the association between the Bayley scores and the neuroclinical assessment, ophthalmologic summary, and imaging findings for the ZIKV-exposed group.

We used chi-squared tests to compare proportions of categorial variables and the Fisher's exact test was used when it was appropriate. Student's $t$-tests were used to compare means differences of continuous variables. The statistical significance level was considered to be $5 \%$ and all testing was two-tailed.

\section{Results}

Of the maternal and clinical-sociodemographic variables compared between the 235 exposed and 39 unexposed control children, only the level of maternal education and children's age at assessment differed between the groups (Table 1). Mothers from the control group had a higher level of education and the children were approximately 4 months older at the time of the BSIDIII assessment.

Table 1. Selected characteristics of mothers and children with prenatal exposure to ZIKV born without microcephaly and the group of controls.

\begin{tabular}{|c|c|c|c|c|c|c|c|}
\hline \multirow[t]{2}{*}{ Variables } & \multicolumn{2}{|c|}{ Total } & \multicolumn{2}{|c|}{ Exposed } & \multicolumn{2}{|c|}{ Controls } & \multirow{2}{*}{$p$-Value } \\
\hline & $n=274$ & $\%$ & $n=235$ & $\%$ & $n=39$ & $\%$ & \\
\hline \multicolumn{8}{|c|}{ Maternal Race/Ethnicity $(n=273)$} \\
\hline Mixed race & 188 & 68.9 & 160 & 68.4 & 28 & 71.8 & \multirow{4}{*}{0.458} \\
\hline White & 51 & 18.7 & 46 & 19.7 & 5 & 12.8 & \\
\hline Black & 31 & 11.4 & 26 & 11.1 & 5 & 12.8 & \\
\hline Other & 3 & 1.1 & 2 & 0.9 & 1 & 2.6 & \\
\hline \multicolumn{7}{|c|}{ Maternal Years of Education $(n=273)$} & \multirow{4}{*}{$<0.001$} \\
\hline $0-8$ years & 98 & 35.9 & 87 & 37.1 & 11 & 28.2 & \\
\hline $9-11$ years & 131 & 48.0 & 119 & 50.9 & 12 & 30.8 & \\
\hline$>12$ years & 44 & 16.1 & 28 & 12.0 & 16 & 41.0 & \\
\hline \multicolumn{7}{|l|}{ Maternal Social Class $(n=262)$} & \multirow{5}{*}{0.812} \\
\hline $\mathrm{A}, \mathrm{B} 1, \mathrm{~B} 2$ & 29 & 11.1 & 24 & 10.7 & 5 & 13.2 & \\
\hline $\mathrm{C} 1$ & 41 & 15.7 & 34 & 15.2 & 7 & 18.4 & \\
\hline $\mathrm{C} 2$ & 101 & 38.5 & 89 & 39.7 & 12 & 31.6 & \\
\hline $\mathrm{D}$ & 91 & 34.7 & 77 & 34.4 & 14 & 36.8 & \\
\hline \multicolumn{7}{|c|}{ Prematurity (Gestational Age < 37 weeks) } & \multirow{3}{*}{$1.00^{\mathrm{a}}$} \\
\hline Yes & 20 & 7.3 & 17 & 7.2 & 3 & 7.7 & \\
\hline No & 254 & 92.7 & 218 & 92.8 & 36 & 92.3 & \\
\hline \multicolumn{7}{|c|}{ Children's Birth Weight $(n=247)$} & \multirow{4}{*}{0.185} \\
\hline$<2500 \mathrm{~g}$ & 23 & 9.3 & 21 & 10.0 & 2 & 5.3 & \\
\hline $2500-2999 \mathrm{~g}$ & 61 & 24.7 & 55 & 26.3 & 6 & 15.8 & \\
\hline$>3000 \mathrm{~g}$ & 163 & 66.0 & 133 & 63.7 & 30 & 78.9 & \\
\hline \multicolumn{7}{|l|}{ Children's Sex } & \multirow{3}{*}{0.674} \\
\hline Female & 139 & 50.7 & 118 & 50.2 & 21 & 50.8 & \\
\hline Male & 135 & 49.3 & 117 & 49.8 & 18 & 46.2 & \\
\hline $\begin{array}{c}\text { Children's Age at Bayley } \\
\text { Assessment (Months) } \\
\text { Mean (SD) }\end{array}$ & 274 & $\begin{array}{l}28.21 \\
(7.35)\end{array}$ & 235 & $\begin{array}{l}27.42 \\
(7.35)\end{array}$ & 39 & $\begin{array}{l}31.59 \\
(6.32)\end{array}$ & $0.001^{a}$ \\
\hline
\end{tabular}


We analyzed the cut-off point $(<-1 \mathrm{SD}$ or score below 85 points) of three domains (cognitive, language, and motor development) as well as the balanced scores of the subtests (cognitive, receptive and expressive communication, and fine and gross motor). The frequency of delays in the cognition domain differed between the groups, with the percentage of delay equal to $9.4 \%(22 / 235)$ for the exposed children, while no child in the control group scored below the cut-off point $(p=0.052)$. This association remained even after adjusting for maternal education and children's age at the Bayley assessment (crude OR $=5.64$; adjusted $\mathrm{OR}=5.95$ ). There was no difference in the percentage of delay for language development $(12.3 \%$ versus $12.8 \%, p=0.933)$. There was an increase in delayed gross and fine motor function in exposed children, but this did not reach statistical significance for the composite and balanced scores. No child presented with evidence of severe delays ( $<-2 \mathrm{SD}$ or score below 70 points) in any domain (Table 2).

Table 2. Neurodevelopment of the group of children with prenatal exposure to ZIKV born without microcephaly and the group of controls based on BSIDIII composite and balanced scores.

\begin{tabular}{|c|c|c|c|c|c|c|c|}
\hline \multirow[t]{2}{*}{ BSIDIII } & \multirow[t]{2}{*}{ Domains } & \multirow[t]{2}{*}{ Test Performance } & \multicolumn{2}{|c|}{$\begin{array}{c}\text { Exposed } \\
n=235\end{array}$} & \multicolumn{2}{|c|}{$\begin{array}{c}\text { Controls } \\
n=39\end{array}$} & \multirow[t]{2}{*}{$p$-Value } \\
\hline & & & $n$ & $\%(C I$ 95\%) & $n$ & $\%(C I 95 \%)$ & \\
\hline \multirow{3}{*}{$\begin{array}{l}\text { Composite } \\
\text { Scores }\end{array}$} & Cognitive & $\begin{array}{c}\text { Adequate } \\
\text { Mild to moderate delay }\end{array}$ & $\begin{array}{c}213 \\
22\end{array}$ & $\begin{array}{c}90.6 \\
9.4(6.3-13.8)\end{array}$ & $\begin{array}{c}39 \\
0\end{array}$ & $\begin{array}{c}100 \\
0\end{array}$ & $0.052^{\mathrm{a}}$ \\
\hline & Language & $\begin{array}{l}\text { Adequate } \\
\text { Mild to moderate delay }\end{array}$ & $\begin{array}{c}206 \\
29\end{array}$ & $\begin{array}{c}87.7 \\
12.3(8.7-17.2)\end{array}$ & $\begin{array}{c}34 \\
5\end{array}$ & $\begin{array}{c}87.2 \\
12.8(5.6-26.7)\end{array}$ & $1.000^{\mathrm{a}}$ \\
\hline & Motor & $\begin{array}{l}\text { Adequate } \\
\text { Mild to moderate delay }\end{array}$ & 224 & $\begin{array}{c}95.3 \\
4.7(2.6-8.2)\end{array}$ & $\begin{array}{c}38 \\
1\end{array}$ & $\begin{array}{c}97.4 \\
2.6(0.5-13.2)\end{array}$ & $1.000^{\mathrm{a}}$ \\
\hline \multirow{4}{*}{$\begin{array}{l}\text { Balanced } \\
\text { Scores }\end{array}$} & Expressive Language & $\begin{array}{c}\text { Adequate } \\
\text { Mild to moderate delay }\end{array}$ & $\begin{array}{c}205 \\
30\end{array}$ & $\begin{array}{c}87.2 \\
12.8(9.1-17.6)\end{array}$ & $\begin{array}{c}31 \\
8\end{array}$ & $\begin{array}{c}79.5 \\
20.5(10.8-35.5)\end{array}$ & 0.195 \\
\hline & Receptive Language & $\begin{array}{l}\text { Adequate } \\
\text { Mild to moderate delay }\end{array}$ & $\begin{array}{l}218 \\
17\end{array}$ & $\begin{array}{c}92.8 \\
7.2(4.6-11.3)\end{array}$ & $\begin{array}{c}36 \\
3\end{array}$ & $\begin{array}{c}92.3 \\
7.7(2.6-20.3)\end{array}$ & $1.000^{\mathrm{a}}$ \\
\hline & Gross Motor & $\begin{array}{l}\text { Adequate } \\
\text { Mild to moderate delay }\end{array}$ & $\begin{array}{c}223 \\
12\end{array}$ & $\begin{array}{c}94.9 \\
5.1(2.9-8.7)\end{array}$ & $\begin{array}{c}38 \\
1\end{array}$ & $\begin{array}{c}97.4 \\
2.6(0.5-13.2)\end{array}$ & $0.701^{\text {a }}$ \\
\hline & Fine Motor & $\begin{array}{l}\text { Adequate } \\
\text { Mild to moderate delay }\end{array}$ & $\begin{array}{c}229 \\
6\end{array}$ & $\begin{array}{c}97.4 \\
2.6(1.2-5.5)\end{array}$ & $\begin{array}{c}39 \\
0\end{array}$ & $\begin{array}{c}100 \\
0\end{array}$ & $0.599^{a}$ \\
\hline
\end{tabular}

In relation to gestational age, $35 / 235(14.9 \%)$ pregnant women had rashes in the first trimester, $67 / 235(28.5 \%)$ in the second trimester, $131 / 235(55.7 \%)$ presented rashes in the third trimester, and two $(0.9 \%)$ were missing information. There was no association between the trimester of rash during pregnancy and the result of the Bayley assessment $(p=0.802)$.

Table 3 considered some clinical and imaging factors that could indicate a higher risk of neurodevelopmental abnormalities. Out of the exposed children with abnormalities on clinical neurological examination, $46.7 \%(14 / 30)$ also had BSIDIII abnormalities in any of the domains (Total Bayley Score). In contrast, the frequency of BSIDIII abnormalities was $17.8 \%(33 / 185)$ for children without neurological alterations $(p=0.001)$. Neither ophthalmologic nor radiologic abnormal findings were significantly associated with delay in any sub-area of the BSIDIII. The neurological alterations most often observed were altered muscle tone, irritability, behavioral complaints, and language delay observed clinically without the use of standardized screening instruments.

Table 3. Clinical and radiological association with performance on the BSID III test in the children with prenatal exposure to ZIKV born without microcephaly.

\begin{tabular}{|c|c|c|c|c|c|c|c|c|}
\hline \multirow{3}{*}{\multicolumn{2}{|c|}{$\begin{array}{c}\text { Clinical and } \\
\text { Radiological Assessment }\end{array}$}} & \multicolumn{7}{|c|}{ Total Bayley Score } \\
\hline & & \multicolumn{2}{|c|}{ Total } & \multicolumn{2}{|c|}{ Adequate Development } & \multicolumn{2}{|c|}{ Delayed Development } & \multirow{2}{*}{$p$-Value } \\
\hline & & $n$ & $(\%)$ & $n$ & $(\%)$ & $n$ & $(\%)$ & \\
\hline \multirow{2}{*}{$\begin{array}{l}\text { Neuroclinical Examination } \\
\qquad(n=215)\end{array}$} & Normal & 185 & 86.1 & 152 & (82.2) & 33 & (17.8) & \multirow{2}{*}{0.001} \\
\hline & Altered & 30 & 13.9 & 16 & (53.3) & 14 & (46.7) & \\
\hline
\end{tabular}


Table 3. Cont.

\begin{tabular}{|c|c|c|c|c|c|c|c|c|}
\hline \multirow{3}{*}{\multicolumn{2}{|c|}{$\begin{array}{l}\text { Clinical and } \\
\text { Radiological Assessment }\end{array}$}} & \multicolumn{7}{|c|}{ Total Bayley Score } \\
\hline & & \multicolumn{2}{|c|}{ Total } & \multicolumn{2}{|c|}{ Adequate Development } & \multicolumn{2}{|c|}{ Delayed Development } & \multirow{2}{*}{$p$-Value } \\
\hline & & $n$ & $(\%)$ & $n$ & $(\%)$ & $n$ & $(\%)$ & \\
\hline \multirow{2}{*}{$\begin{array}{l}\text { Ophthalmologic findings } \\
\qquad(n=172)\end{array}$} & Normal & 154 & 89.5 & 113 & $(73.4)$ & 41 & $(26.6)$ & \multirow{2}{*}{$1.000^{\mathrm{a}}$} \\
\hline & Altered & 18 & 14.5 & 13 & (72.2) & 5 & (27.8) & \\
\hline \multirow{2}{*}{$\begin{array}{l}\text { Imaging findings } \\
\quad(n=142)\end{array}$} & Normal & 126 & 88.7 & 98 & $(77.8)$ & 28 & $(22.2)$ & \multirow{2}{*}{$0.529^{a}$} \\
\hline & Altered & 16 & 11.3 & 11 & (68.7) & 5 & (31.3) & \\
\hline
\end{tabular}

a Fisher's exact test.

Abnormalities at neuroclinical examination were associated with delays in the language and motor domains ( $p=0.003$ and $p=0.008$, respectively), but showed no association with cognitive development (Table 4 ).

Table 4. Association between Bayley's test and neuroclinical examination in the children with prenatal exposure to ZIKV born without microcephaly.

\begin{tabular}{|c|c|c|c|c|c|}
\hline \multirow{3}{*}{$\begin{array}{l}\text { Neuroclinical } \\
\text { Examination }\end{array}$} & \multicolumn{4}{|c|}{ Bayley III Subscales } & \multirow{3}{*}{$p$-Value } \\
\hline & \multicolumn{2}{|c|}{ Adequate Development } & \multicolumn{2}{|c|}{ Delayed Development } & \\
\hline & $n$ & $(\%)$ & $n$ & $(\%)$ & \\
\hline \multicolumn{6}{|c|}{ Cognition } \\
\hline Normal & 171 & $(92.4)$ & 14 & $(7.6)$ & $0.105^{\mathrm{a}}$ \\
\hline Altered & 25 & $(83.3)$ & 5 & $(16.7)$ & \\
\hline \multicolumn{6}{|c|}{ Language } \\
\hline Normal & 169 & $(91.4)$ & 16 & $(8.6)$ & $0.003^{\mathrm{a}}$ \\
\hline Altered & 21 & $(70.0)$ & 9 & $(30.0)$ & \\
\hline \multicolumn{6}{|c|}{ Motor } \\
\hline Normal & 182 & $(98.4)$ & 3 & $(1.6)$ & 0.008 \\
\hline Altered & 26 & $(86.7)$ & 4 & (13.3) & \\
\hline
\end{tabular}

a Fisher's exact test.

\section{Discussion}

We present the results from neurodevelopmental evaluation of one of the largest samples ever studied relative to children exposed to ZIKV without microcephaly compared to a control group without prenatal ZIKV exposure. Using the BSIDIII cut-off point, we observed a slightly statistically significant difference for cognition, with mild to moderate delay in $9.4 \%$ of exposed children and $0.0 \%$ of the control group. Regarding language and motor, the percentage of delays did not differ between the exposed and the controls. In exposed children, the neuroclinical examination was predictive of neurodevelopment delay and showed significant association with the BSIDIII for the language and motor function domains.

Although the ZIKV epidemic in Brazil (2015-2016) has provided increasing scientific knowledge about CZS, later repercussions on neurodevelopment still require further observation and follow-up time to be completely understood. CZS is considered as a spectrum of manifestations, with severity related to the degree of microcephaly as well as other structural brain malformations $[11,18,19]$. Some authors have described the severe and early neurological impairment of children born with microcephaly, for whom more than $90 \%$ may present with neurodevelopmental delays $[4,6,20]$. Similar patterns have been observed in children born with normal head circumference who presented with decelerated growth rates and developed microcephaly within the first months of life [21].

The aim of this study was to evaluate children in a population unlike those previously mentioned. This study advances our knowledge by comparing children with evidence of maternal ZIKV infection during pregnancy but without microcephaly to a control group 
without evidence of maternal ZIKV infection during pregnancy born in the same region and period of time with similar sociodemographic characteristics.

Our overall results are consistent with another Brazilian study, which analyzed a smaller sample and reported a difference between groups concerning the cognitive domain but not for the motor and language domains [8]. Pursuing a more detailed comparison between groups, we analyzed the outcomes of the BSIDIII subtests using balanced scores for receptive and expressive communication as well as gross and fine Motor; the frequency of delays in these subtests did not differ significantly between the exposed and unexposed groups.

A survey conducted in Rio de Janeiro, Brazil, evaluated 146 ZIKV exposed children with the BSIDIII test and found that $28 \%$ presented with a mild to moderate delay in at least one domain of the composite BSIDIII score. Twelve percent of this sample scored below -2 SD (i.e., indicating severe delays) in at least one of the domains; the group with severe delays included six children with microcephaly and three who developed autism in the second year of life [22]. Another group of researchers evaluated a smaller sample of 26 children without microcephaly, but with other comorbidities such as macrocephaly and co-infections with HIV and toxoplasmosis and found the frequency of abnormal BSIDIII results in at least one domain to be $34.6 \%$ [23]. In our study, we did not observe severe impairment in any child and the percentage of delay for the three domains was less than those previously mentioned: at $9.4 \%$ for cognition, $12.3 \%$ for language, and $4.7 \%$ for motor development. It is likely that such difference resulted from the fact that we assessed a more homogeneous sample that excluded children with microcephaly or other severe disorders.

Another study applied BSIDIII to children exposed in utero to ZIKV paired with an external control group [24]. Developmental abnormalities were detected in $17.8 \%$ of the cases, while $100 \%$ of the controls scored above the cut-off point for delays. In that study, there was a substantial difference between the two groups, possibly because the control group was taken from an Austrian routine database. Meanwhile, our total sample was composed of Brazilian children from the same state who were predominantly from a disadvantaged social background.

The fact that this research took place in the state of Pernambuco, Brazil, which is the epicenter of the microcephaly epidemic, made it possible to evaluate a large and homogeneous sample. As for perinatal and sociodemographic factors, we detected only a slight increase in maternal education level for the control group. Another aspect differing between the groups is the mean age at the assessment time, which was 4 months older in the unexposed group compared to the exposed group. Although the literature frequently shows an impact of these factors on child development, in our study the slight association observed between in utero exposure to ZIKV and cognitive development remained even after adjusting for both maternal education and children's age.

Since the present study is a cross-sectional study nested in a cohort, several aspects beyond neuropsychomotor development were assessed over time. When designing the study, we took into consideration the various clinical presentations of congenital ZIKV infection, which required detailed clinical evaluation essential to address the lack of knowledge about the disease at that time. Thus, the research group emphasized not only the application of the BSIDIII but also a detailed neurological assessment conducted with a standardized form, including a detailed history, physical examination, and developmental milestones. Our sample was also carefully followed up regarding radiological and ophthalmological aspects.

Among the exposed children, the neuroclinical examination was the only one of the three sets of variables tested (i.e., with the others being ophthalmologic and imaging) that showed significant association with the BSIDIII for the language and motor function domains. The lack of association with the cognitive domain may be due to the difficulty in assessing it in isolated form since cognition is predominantly verified by sensory-motor skills in the first years of life. Children only start to appropriate the body schema and elaborate mental representations of the surrounding environment after the third year of life. 
Of the 215 exposed children, 30 (14\%) had some abnormalities upon traditional clinical neurological assessment. Hypotonia, speech delay, irritability, sleep pattern changes, and inadequate visual response were the main complaints. Among the children with normal neurological examinations, $82 \%$ had an appropriate development, whereas in those with altered neurological examination only $53 \%$ had appropriate development. Therefore, abnormal neuroclinical examination indicated a markedly higher risk of neurodevelopmental delay in our study.

BSIDIII is considered a complex assessment. It is a difficult-to-apply and high-cost instrument that requires specific training and therefore is not available in most public services. Thus, we emphasize the importance of detailed clinical neurological examination as a tool to detect neurodevelopmental delays, which will enable the early identification and referral of children who require comprehensive assessment. The comprehensive neurological evaluation enables a better use of resources and the earliest possible intervention.

We found no association between ophthalmologic testing in the exposed group and Bayley outcome, which is different from findings among children with ZIKV-related microcephaly where a large percentage had severe visual impairment and neurodevelopmental delay. Of the 18 exposed children with altered ophthalmological examinations, 13 had a normal neurodevelopmental assessment (72.2\%).

Except for serological tests and brain ultrasounds, additional tests were only requested as clinically indicated because of the ethical implications of the risk inherent to procedures under sedation in children. This explains the proportion of children without brain imaging and could account for the lack of association between neuroradiological findings and neurodevelopmental outcomes. Of the 16 children from the exposed group who exhibited altered brain ultrasounds (i.e., with calcifications, cerebellar hypoplasia and/or atrophy, and agenesis and/or dysgenesis of the corpus callosum and/or diffuse cortical atrophy), only two showed clinical changes which manifested as irritability in addition to developmental delay by the BSIDIII. Conversely, Moreira and colleagues identified a significant association between normal brain imaging and delays identified in the BSIDIII test [25].

Our study assessed a large and well-characterized sample of children born to women with laboratory evidence of ZIKV infection during pregnancy and without microcephaly who represented a relatively homogeneous and deprived sociodemographic background. These children were born at the epicenter of the ZIKV epidemic and represent a group that is still poorly studied in terms of neuropsychomotor development, especially because CZS is a novel disease for which the natural history is still being defined. Our comparison group was smaller, and this may have contributed to the lack of statistical significance of the observed increase in motor development delays. Another limitation is due to the fact that the children from the control group were born to mothers who were tested only at the time of delivery, rather than prospectively throughout pregnancy.

Overall, our findings suggest that relative to their unexposed peers, the ZIKV-exposed children without microcephaly are not at considerably increased risk of neurodevelopmental impairment in the first 42 months of life. However, a small group of children did demonstrate higher frequencies of cognitive delay, with a borderline significance. It is important to highlight that in the group of exposed children, an abnormal neuroclinical examination may be a predictor of developmental delay. However, it is also noteworthy that not all ZIKV-exposed children develop brain damage or suffer long-term neurodevelopmental impairment. These findings combined with the knowledge that children born in the epidemic are still at preschool age reinforces the importance of continued follow-up and detailed paediatric and neurological evaluation in the longer term, since there is still not enough knowledge about late-onset manifestations or more mild impairments that are not noticeable in the early years but exacerbated later, such as attention deficit hyperactivity disorder, autism, learning disability, and behavioral changes.

Author Contributions: Conceptualization, D.d.B.M.-F., S.H.E., E.B.B., C.M.T.M., U.R.M., P.F.S.d.S., L.C.R. and R.A.d.A.X.; methodology, D.d.B.M.-F., E.B.B., C.M.T.M., L.C.R., U.R.M., S.H.E., P.F.S.d.S. and R.A.d.A.X.; formal analysis, D.d.B.M.-F., P.F.S.d.S., S.H.E., C.M.T.M., U.R.M., M.C.L. and 
R.A.d.A.X.; investigation, L.O.V., S.H.E., P.F.S.d.S., M.D.C.G.d.C., R.C.F.R. and D.M.d.S.O.; data curation, U.R.M.; supervision, D.d.B.M.-F., E.B.B., C.M.T.M., T.V.B.d.A., S.H.E. and R.A.d.A.X.; project administration, D.d.B.M.-F., S.H.E., C.M.T.M., T.V.B.d.A., U.R.M. and R.A.d.A.X.; funding acquisition, D.d.B.M.-F., T.V.B.d.A., C.M.T.M., L.C.R., E.B.B. and R.A.d.A.X.; writing-original draft preparation and review and editing, all authors. All authors have read and agreed to the published version of the manuscript.

Funding: This study was supported by the European Union's Horizon 2020 Research and Innovation programme (https:/ / ec.europa.eu/programmes/horizon2020/ Accessed on 10 June 2021) under ZikaPLAN grant agreement (No. 734584), (https:/ / zikaplan.tghn.org/ Accessed on 10 June 2021); Wellcome Trust and the UK Department for International Development (201870/Z/16/Z and 205377/Z/16/Z; https:/ / wellcome.ac.uk / Accessed on 10 June 2021); Wellcome Trust-Research Enrichment in Epidemic Situations (107779/Z/15/Z; ER1505 and ER1601); Medical Research Council on behalf of the Newton Fund and Wellcome Trust (MC_PC_15088; https://mrc.ukri.org/ Accessed on 10 June 2021); U.S. National Institute of Child Health and Human Development (NICHD), National Institute of Allergy and Infectious Diseases (NIAID), National Institute of Environmental Health Sciences (NIEHS), and Fundação Oswaldo Cruz-Fiocruz, Brazil (to the International Prospective Observational Cohort Study of Zika in Infants and Pregnancy-ZIP Study), grant number: HHSN275201800001I; Brazilian Ministry of Health, Pan American Health Organization, and Enhancing Research Activity in Epidemic Situations (to the MERG Case Control Study); Fundação de Amparo à Ciência e Tecnologia de PE-FACEPE (APQ-0192-4.01/17 to Programa de Pós-graduação em Ciências da Saúde-UPE and APQ-0172-4.01/16 to DBMF; http:/ / www.facepe.br/ Accessed on 20 July 2021); Coordenação de Aperfeiçoamento de Pessoal de Nível Superior-Brasil (CAPES)— Finance Code 001; Scholarship: Conselho Nacional de Desenvolvimento Científico e Tecnológico (309722/2017-9 to RAAX, 306708/2014-0 to CMTM; http:/ /www.cnpq.br/ Accessed on 20 July 2021); Secretaria de Vigilância em Saúde/Ministério da Saúde de Brasil Resposta à Emergência em Saúde Pública-Zika vírus e Microcefalia (837058/2016 to RAAX); Conselho Nacional de Desenvolvimento Científico e Tecnológico, Coordenação de Aperfeiçoamento de Pessoal de Nível Superior (http:/ / www.capes.gov.br/ Accessed on 10 June 2021); Departamento de Ciência e Tecnologia (http:/ / rebrats.saude.gov.br/noticias/59 Accessed on 20 July 2021) Accessed 20 June 2021 for Prevenção e Combate ao vírus Zika I (440839/2016-5 to RAAX). The funders had no role in study design, data collection, and analysis or in the decision to publish or the preparation of the manuscript.

Institutional Review Board Statement: The study was conducted according to the guidelines of the Declaration of Helsinki and is approved by the Institutional Review Board of Faculdade de Ciências Médicas da Universidade de Pernambuco CAAE 52803316.8.0000.5192 on 3 February 2016.

Informed Consent Statement: Informed consent was obtained from the guardians of all subjects involved in the study.

Data Availability Statement: Data cannot be shared. Public availability of the data would compromise patient privacy. De-identified data can be made available upon reasonable request from qualified investigators by contacting the Programa de Pós-Graduação em Ciências da Saúde (PPGCS) da Universidade de Pernambuco (UPE) at ppg.cienciasdasaude@upe.br.

Acknowledgments: We are grateful to all participants, researchers, and fieldworkers for their ongoing commitment to the MERG-PC study. We are also grateful to Altino Ventura Foundation and to the Hospital Universitário Oswaldo Cruz and Instituto Aggeu Magalhães-Fiocruz/PE for providing the infrastructure for the clinical and/or laboratory assessments of the children for this study.

Conflicts of Interest: The authors declare no conflict of interest.

\section{References}

1. Saad, T.; PennaeCosta, A.A.; De Góes, F.V.; De Freitas, M.; De Almeida, J.V.; Ignêz, L.J.D.S.; Amancio, A.P.; Alvim, R.J.; Kramberger, L.A.A. Neurological manifestations of congenital Zika virus infection. Childs Nerv. Syst. 2017, 34, 73-78. [CrossRef] [PubMed]

2. De Brito, C.A.A.; Cordeiro, M.T. One year after the Zika virus outbreak in Brazil: From hypotheses to evidence. Rev. Soc. Bras. Med. Trop. 2016, 49, 537-543. [CrossRef] [PubMed]

3. de Barros Miranda-Filho, D.; Martelli, C.M.T.; de Alencar Ximenes, R.A.; Araújo, T.V.B.; Rocha, M.A.W.; Ramos, R.C.F.; Dhalia, R.; de Oliveira França, R.F.; de Azevedo Marques Júnior, E.T.; Rodrigues, L.C. Initial Description of the Presumed Congenital Zika Syndrome. Am. J. Public Health 2016, 106, 598-600. [CrossRef] [PubMed] 
4. Alves, L.V.; Paredes, C.E.; Silva, G.C.; Mello, J.G.; Alves, J.G. Neurodevelopment of 24 children born in Brazil with congenital Zika syndrome in 2015: A case series study. BMJ Open 2018, 8, e021304. [CrossRef]

5. $\quad$ Lage, M.-L.C.; De Carvalho, A.L.; Ventura, P.A.; Taguchi, T.B.; Fernandes, A.S.; Pinho, S.F.; Santos-Junior, O.T.; Ramos, C.L.; Nascimento-Carvalho, C.M. Clinical, Neuroimaging, and Neurophysiological Findings in Children with Microcephaly Related to Congenital Zika Virus Infection. Int. J. Environ. Res. Public Health 2019, 16, 309. [CrossRef] [PubMed]

6. Carvalho, A.; Brites, C.; Mochida, G.; Ventura, P.; Fernandes, A.; Lage, M.L.; Taguchi, T.; Brandi, I.; Silva, A.; Franceschi, G.; et al. Clinical and neurodevelopmental features in children with cerebral palsy and probable congenital Zika. Brain Dev. 2019, 41, 587-594. [CrossRef]

7. Baud, D.; Gubler, D.J.; Schaub, B.; Lanteri, M.C.; Musso, D. An update on Zika virus infection. Lancet 2017, 390, 2099-2109. [CrossRef]

8. Ticona, J.P.A.; Nery, N.; Ladines-Lim, J.B.; Gambrah, C.; Sacramento, G.; Freitas, B.D.P.; Bouzon, J.; Oliveira-Filho, J.; Borja, A.; Adhikarla, H.; et al. Developmental outcomes in children exposed to Zika virus in utero from a Brazilian urban slum cohort study. PLoS Negl. Trop. Dis. 2021, 15, e0009162. [CrossRef]

9. Kapogiannis, B.G.; Chakhtoura, N.; Hazra, R.; Spong, C.Y. Bridging Knowledge Gaps to Understand How Zika Virus Exposure and Infection Affect Child Development. JAMA Pediatr. 2017, 171, 478-485. [CrossRef]

10. Miranda-Filho, D.D.B.; Brickley, E.; Ramond, A.; Martelli, C.; Clemente, N.S.; de Araújo, T.V.B.; Rodrigues, L.; Montarroyos, U.; de Souza, W.; de Albuquerque, M.; et al. The Microcephaly Epidemic Research Group Paediatric Cohort (MERG-PC): A Cohort Profile. Viruses 2021, 13, 602. [CrossRef]

11. Da Silva, P.F.S.; Eickmann, S.H.; Ximenes, R.A.D.A.; Montarroyos, U.R.; Lima, M.D.C.; Martelli, C.M.T.; De Araújo, T.V.B.; Brickley, E.B.; Rodrigues, L.C.; Gonçalves, F.C.L.D.S.P.; et al. Pediatric neurodevelopment by prenatal Zika virus exposure: A cross-sectional study of the Microcephaly Epidemic Research Group Cohort. BMC Pediatr. 2020, 20, 1-11. [CrossRef]

12. Madaschi, V.; Mecca, T.P.; Macedo, E.C.; Paula, C.S. Bayley-III Scales of Infant and Toddler Development: Transcultural Adaptation and Psychometric Properties. Paidéia 2016, 26, 189-197. [CrossRef]

13. Bayley, N. Bayley Scales of Infant and Toddler Development, 3rd ed.; Harcourt Assessment: San Antonio, TX, USA, 2006.

14. de Araújo, T.V.B.; Ximenes, R.A.D.A.; Miranda-Filho, D.D.B.; Souza, W.; Montarroyos, U.R.; de Melo, A.P.L.; Valongueiro, S.; Albuquerque, M.D.F.P.M.D.; Braga, C.; Filho, S.B.; et al. Association between microcephaly, Zika virus infection, and other risk factors in Brazil: Final report of a case-control study. Lancet Infect. Dis. 2018, 18, 328-336. [CrossRef]

15. Ximenes, R.A.D.A.; Miranda-Filho, D.D.B.; Brickley, E.B.; Montarroyos, U.R.; Martelli, C.M.T.; De Araújo, T.V.B.; Rodrigues, L.C.; Albuquerque, M.D.F.P.M.D.; De Souza, W.V.; Castanha, P.; et al. Zika virus infection in pregnancy: Establishing a case definition for clinical research on pregnant women with rash in an active transmission setting. PLoS Negl. Trop. Dis. 2019, 13, e0007763. [CrossRef] [PubMed]

16. Ximenes, R.A.D.A.; Miranda-Filho, D.D.B.; Montarroyos, U.R.; Martelli, C.M.T.; de Araújo, T.V.B.; Brickley, E.; Albuquerque, M.D.F.P.M.D.; Souza, W.V.; Ventura, L.O.; Ventura, C.V.; et al. Zika-related adverse outcomes in a cohort of pregnant women with rash in Pernambuco, Brazil. PLoS Negl. Trop. Dis. 2021, 15, e0009216. [CrossRef] [PubMed]

17. Rubio-Codina, M.; Araujo, M.C.; Attanasio, O.; Muñoz, P.; Grantham-McGregor, S. Concurrent Validity and Feasibility of Short Tests Currently Used to Measure Early Childhood Development in Large Scale Studies. PLoS ONE 2016, 11, e0160962. [CrossRef]

18. Pool, K.-L.; Adachi, K.; Karnezis, S.; Salamon, N.; Romero, T.; Nielsen-Saines, K.; Pone, S.M.; Boechat, M.; Aibe, M.; Da Silva, T.G.; et al. Association Between Neonatal Neuroimaging and Clinical Outcomes in Zika-Exposed Infants From Rio de Janeiro, Brazil. JAMA Netw. Open 2019, 2, e198124. [CrossRef]

19. de Fatima Vasco Aragao, M.; Van Der Linden, V.; Brainer-Lima, A.M.; Coeli, R.R.; Rocha, M.A.; Da Silva, P.S.; De Carvalho, M.D.C.G.; van der Linden, A.; De Holanda, A.C.; Valenca, M.M. Clinical features and neuroimaging (CT and MRI) findings in presumed Zika virus related congenital infection and microcephaly: Retrospective case series study. BMJ 2016, 353, i1901. [CrossRef]

20. Wheeler, A.C.; Toth, D.; Ridenour, T.; Nóbrega, L.L.; Firmino, R.B.; Da Silva, C.M.; Carvalho, P.; Marques, D.; Okoniewski, K.; Ventura, L.O.; et al. Developmental Outcomes Among Young Children With Congenital Zika Syndrome in Brazil. JAMA Netw. Open 2020, 3, e204096. [CrossRef]

21. Van Der Linden, V.; Pessoa, A.; Dobyns, W.; Barkovich, A.J.; Junior, H.V.D.L.; Filho, E.L.R.; Ribeiro, E.M.; Leal, M.D.C.; Coimbra, P.P.D.A.; Aragão, M.D.F.V.V.; et al. Description of 13 Infants Born During October 2015-January 2016 With Congenital Zika Virus Infection Without Microcephaly at Birth-Brazil. MMWR. Morb. Mortal. Wkly. Rep. 2016, 65, 1343-1348. [CrossRef]

22. Nielsen-Saines, K.; Brasil, P.; Kerin, T.; Vasconcelos, Z.; Gabaglia, C.R.; Damasceno, L.; Pone, M.V.D.S.; De Carvalho, L.M.A.; Pone, S.M.; Zin, A.A.; et al. Delayed childhood neurodevelopment and neurosensory alterations in the second year of life in a prospective cohort of ZIKV-exposed children. Nat. Med. 2019, 25, 1213-1217. [CrossRef] [PubMed]

23. Abtibol-Bernardino, M.; Peixoto, L.D.A.; De Oliveira, G.; De Almeida, T.; Rodrigues, G.; Otani, R.; Chaves, B.S.; Rodrigues, C.D.S.; De Andrade, A.; Redivo, E.D.F.; et al. Neurological Findings in Children without Congenital Microcephaly Exposed to Zika Virus in Utero: A Case Series Study. Viruses 2020, 12, 1335. [CrossRef] [PubMed] 
24. Einspieler, C.; Utsch, F.; Brasil, P.; Aizawa, C.Y.P.; Peyton, C.; Hasue, R.H.; Genovesi, F.F.; Damasceno, L.; Moreira, M.E.; Adachi, K.; et al. Association of Infants Exposed to Prenatal Zika Virus Infection With Their Clinical, Neurologic, and Developmental Status Evaluated via the General Movement Assessment Tool. JAMA Netw. Open 2019, 2, e187235. [CrossRef] [PubMed]

25. Moreira, M.E.L.; Nielsen-Saines, K.; Brasil, P.; Kerin, T.; Damasceno, L.; Pone, M.V.D.S.; Carvalho, L.M.; Pone, S.M.; Vasconcelos, Z.; Ribeiro, I.P.; et al. Neurodevelopment in Infants Exposed to Zika Virus In Utero. N. Engl. J. Med. 2018, 379, 2377-2379. [CrossRef] [PubMed] 